\title{
Parental Support in Career Development of Youths with Intellectual Disabilities in Selected Skills Training Institutions in Zambia: Are Parents Practitioners?
}

\author{
Mathatha Viola, Ndhlovu Daniel \\ School of Education, Kwame Nkrumah and University of Zambia
}

*Corresponding Author: Mathatha Viola, School of Education, Kwame Nkrumah and University of Zambia

\begin{abstract}
This paper discuses parental support in career development of youths with intellectual disabilities in selected skills training institutions in Zambia and whether parents are practitioner. The descriptive case study was carried out in Kabwe, Chisamba and Ndola districts of Central and Copperbelt Provinces respectively. Purposive sampling was used on a population of 390 to select 60 respondents: 15 youths with intellectual disabilities, their lecturers (15) and their parents (30). Semi-structured interviews, observation and focus groups discussions were used to collect data. Data analysis was done thematically. The study revealed that factors that affect parental support are income, parenting style, parental expectations, education, knowledge levels and the nature of disability. Parental support was found to influence career development through being motivational and encouraging. As to whether parents were practitioners of support, it was found that most parents were not. Although parents had knowledge of their role of supporting their children, it was low. The situation was attributed to low levels of knowledge and low expectations. Based on the findings, the study recommends that education providers sensitize parents on intellectual disability. To ensure parents are supportive, the Ministry of General Education should form a Network Support System for parents of children with intellectual disabilities.
\end{abstract}

Keywords: Career Development, Intellectual Disability, Parent, Support

\section{INTRODUCTION}

Career development of an individual with or without disabilities begins in early childhood from the environment (family). It is a life span process which the family continues to have an influence and it is within the family that children with or without disabilities learn about the world of work (Kerka, 2000).

According to the World Health Organization (WHO, 2011), Intellectual disability is a generalized neurological disorder characterized by significantly impaired intellectual and adaptive functioning. Despite challenges in their performance, individuals with Intellectual Disabilities can, and do, go on to succeed in education and employment (Ansbery, 2010). In spite of such accessions, employment statistics by WHO (2015) indicate that the rate of employment for youths with disabilities in developed and underdeveloped countries is lower than that of those without disabilities. While the International Labour Organization (ILO) (2015) estimates of general unemployment of young persons to at least 88 million (47\%) out of all the 186 million unemployed persons globally, the unemployment rates among persons with disabilities is as high as $80 \%$ in most countries.

Although attitudes have changed which have seen individuals with intellectual disabilities being accepted in families, offered education and training, much has been left to Non-Governmental Organisations (NGOs) and churches (Habour \& Maulik, 2010). The parents who are the primary care givers and educators seem to play a low profile. Yet, Kerka (2000) argues that children learn to interpret the world of work within the family where they live.

Parents play a significant role in the career development of adolescents (Whiston \& Keller, 2008). Although the majority of studies were conducted with white middle class individuals, results have often been used to make assumptions about parental influence of parental support in the career development of children in general.This has presented a possibility biased view of the particular 
parental influence components that may be crucial for Zambian youths. The limited research in this area has shown that parental support is an important factor that influences career development of adolescents (Whiston \& Keller, 2008; Ginevra \& Nota, 2011).

In Zambia, as the business economy and the labour force respond to the changing economy, people with intellectual disabilities must not only be part of the economy conversation but they must be active participants in filling the increased need for skilled workers. Nord (2012) suggests that families should be providers, leading the way as supporters of career development of their children. There is a conspicuous gap in literature where we would expect and hope to find issues of parental support in career development of youths with intellectual disabilities. Although there has been research in some developing countries addressing parental support and career development children with intellectual disabilities and their hopes for the future, there has not been such in Zambia. Since little is known in this area, the study sought to fill in the gap.

\subsection{Statement of the Problem}

Before the $18^{\text {th }}$ century, children with intellectual disabilities were left to die of exposure as infants rather than permitted to grow up (Harbour \& Maulik, 2010). Although the early 1800 optimism prevailed for training, rehabilitating and integrating individuals with intellectual disabilities to normal life, youths with intellectual disabilities continue to be neglected across most countries (Harbour \& Maulik, 2010). They also face the largest hurdles to enter the workforce and as a result experience the highest unemployment rate (Butterfield, Hall, Smith, Migliore, Winsor, Timmon \& Domin, 2011; WHO, 2011; ILO, 2012). In Zambia, they are not in employment or are in family businesses with little or no pay at all (CSO, 2012). Nord (2012) notes that in today's climate, supporting our loved ones in shaping their future has to start with families. With this in mind, the study sought to investigate the influence of parental support in career development of youths with intellectual disabilities and whether parents are practitioners.

\subsection{Purpose of the Study}

The purpose of this study was to investigate the influence of parental support on career development of youths with intellectual disabilities and whether parents are practitioners.

\subsection{Objectives}

The objectives were to:

1. To determine the factors that affect parental support.

2. To establish how parents influences career development of youths with intellectual disabilities.

3. To determine parental support practices in the career development of youths with intellectual disabilities.

\subsection{Research Questions}

The following questions guided the study:

1. What are the factors affect parental support?

2. How does parental support influence career development of youths with intellectual disabilities?

3. What are parental support practices in the career development of youths with intellectual disabilities?

\subsection{Theoretical Framework}

The study was guided by the Ecological Systems Theory by Urie Bronfenbrenner (1999) which assumes that development is best understood by examining ones context. Bronfenbrenner believes that career development is a lifelong process of getting ready to choose, choosing and typically continuing to make choices from among many occupations in our society. This depends so much on the heterogeneity of individuals and is influenced by the context in which they live. The theory advocates that the environment has direct influence on an individual's development. The theory states that a person's ability to reach their potential is dependent on the presence of opportunities in the settings in which he or she lives. It argues that individuals better adjust and are more satisfied in 
environments that match their attitudes, values, goals and experiences, that is, they are more satisfied when there is a fit between themselves and their environment (Schutheiss, Kress, Manzi \& Glasscock, 2001). Being congruent with one's parents on career matters reflects a fit between individuals and their environment. Such a fit is likely to facilitate and foster career development (Duffy \& Dik, 2009). Incongruity or lack of fit on the other hand is a potential external barrier to career development (Schutheiss, et al., 2001). In addition, real life situations provide either opportunities or barriers to career development. The theory assumes that parents influence career development through interactions, relationships and expectations they create with their children. The more encouraging and nurturing these relationships, interactions and places are, the better the child will be able to develop careers.

The theory has five systems: microsystem, exosystem, mesosystem macrosytem and chronosystem. These helped understand the role of parental support in career development of youths with intellectual disabilities. The ecological systems theory to help understand how parents can help successfully support students educational and vocational development.

\subsection{Significance of the Study}

Findings may contribute to the knowledge gap of the significant role of parental support in career development of youths with intellectual disabilities. Findings may reveal to policy makers and implementer about the parental support knowledge and whether practice in career development of youths with intellectual disabilities.

\section{LITERATURE REVIEW}

Support includes all experiences that enhance career development such as provisions of resources. Parental support has a significant positive impact on a child's career developmental process, future plans and career goals. Turner, Aliman, Lapan, Udipi and Ergun (2003) found that supportive behaviour contributes significantly to young adolescents' making better career choices. Turner's findings have also shown that adolescents' perceptions of parental support in the pursuit of future occupations were significant predictors of their interests, vocational self-efficacy and valuing of certain occupations (Turner et al., 2003). Though conducted 14 years ago, the current researchers wondered whether results would be replicated in Zambia on youths with intellectual disabilities.

Some influence of parental support and encouragement for career choices of adolescents may also be discerned from another study, indicating that the type of involvement the parents have is correlated with the willingness of adolescents and young adults to be comfortable trekking down an occupational path that might not be the first choice of one or both parents. In Cuiting and Kerpelman (2007)'s study, questionnaires were administered to 304 female undergraduates regarding parental feedback to the young adults and their parents' willingness to discuss and support their career choices. The researchers concluded that this willingness for the parent to positively engage in supportive career discussions influenced young women's certainty about pursuing particular careers. However, this study was conducted on female undergraduate youths without disabilities and it made use of questionnaires. It is not known whether similar results would be yielded if conducted on youths with intellectual disabilities in Zambia with the use of interviews.

Hairston (2000)'s study on African-American parents showed that all respondents indicated a sense of parental support for their vocational teaching career that encouraged children to seek and complete pursuit of a teaching career. In addition, parental support indicated career choice approval and elicited expressions of pride among respondents as they witnessed their parents esteem for vocational teaching. Parental support was additionally motivating in respondent's vocational student's organised activities. The current study is on African youths with intellectual disabilities in skills training institutions,

In 2011, Ginevra and Nota, using Social Cognitive Career Theory (SCCT) examined the role of parents' and children's perceptions of parental support in adolescents' career choices. A total of 94 Italian adolescents (30 boys, 64 girls) and both of their parents $(\mathrm{N}=188)$ participated in the study. The authors tested a fully mediated model between mothers' and fathers' perceptions of support and career choice through the indirect effect of adolescents' perceptions of parental support and career self-efficacy. Specifically, both mothers' and fathers' perceptions of support predicted their 
adolescents' career choice through the mediating effect of the youths' perceptions of parental support and career self-efficacy. These results have important implications for practice and underscore that parents need to be involved very early on in their children's vocational development. However, the study used the SCCT on boys and girls without disabilities and their parents without their teachers. The current study makes use of the ecological theory on youths with intellectual disabilities, their parents and their lecturers. The study uses qualitative methods and is conducted on youths with intellectual disabilities aged between 19-35 to ascertain if parents are practitioners of parental support in career development of their children.

Kniveton (2004) discussed how parents provide the strongest influences on their children's career development through support and advice related to their own experiences. Kniveton believed in the theory that not all people feel they have free choice when it comes to choosing a career. He used a relatively short questionnaire. The items were all measured with Likert type scale responses to interview 348 young people (174 males/174 females; ages 14-18 with a mean of 16.7 years) to help explore who these young adults felt were helping them with their career exploration. The results of Kniveton's study also showed that parents had a much larger influence than that of the teachers. Though conducted over a decade later with the belief that the child's development is influenced by the environment in which he or she lives (family), it is also important to note that the study's respondents were youths with intellectual disabilities, their lecturers and parents. In addition it seeks to establish whether parents are practitioners of support to enhance career development of their children.

Olaosebikan and Makopela (2014) conducted a study to investigate the effects of parental influence on adolescents career choices on secondary school students in Badagry Local government area of Lagos State, Nigeria. The sample consisted of 300 randomly selected students from 10 purposively selected secondary schools; 3 model colleges, 4 non model colleges and 3 private colleges. The study used a questionnaire. Five null hypotheses were formulated and tested. Chi square analysis contingency table was used to test the hypothesis at 0.05 level of significance of variables. Findings showed that without parental support, youths are often reluctant to pursue or explore diverse career possibilities. The 2014 study looked at parental influence on adolescents' career choices while the current study looks at whether parents practice support to enhance career development of their children.

Whiston and Keller (2004) conducted a study on the role of parental influence on middle school students' career development using a logistic regression. The study revealed that the positive influence of support from parents positively influences career development. The study also indicates that in addition to support and love, communication and honesty are important to career development. It is important to note that this study seeks to determine whether parents of children with intellectual disabilities are practitioners of parental support.

One Finnish study interrelates how the adolescents' motivation and what the adolescents thought about the career development compared with the degree of their parents involvement in their career preparation (Dietrich \& Salmela-Aro, 2013). Parental warmth and career preparation involvement was correlated to less stress by the adolescents in later years regarding their career decisions. Adolescents were more likely able to pursue the careers they were interested in and motivated to pursue if their parents were involved in supporting and assisting them in their aspirations and those youth had less stress related to their career decisions. These are of course Finnish adolescents and young adults, which may or may not be descriptive of youths with intellectual disabilities in Zambia. Secondly, the researchers in this study wondered whether parents are practitioners of this support to their children.

A study was performed regarding what factors influenced an aspiration for a science career by 14-15 year old youth, (Rodrigues, Jindal-Snape \& Snape, 2011). The study concluded that the most important factor influencing the aspiration of a science career by the adolescents is their perception as to whether their parents want them to pursue such a career. This study illustrates the difficulty of trying to determine if career development and choice in for example, youth with intellectual disabilities is influenced by the specific parental involvement in the career development of their children or in the style the parents use in the general overall raising of their children in the Zambian set up. It is not known whether there is causation involved here in which parents wish for their children to pursue a career at a skills training institution, so the children aspire to such a career, or if 
these parents are supportive of whatever career choice their children express. The 2011 study centered only on science career while this study's respondents are in skills training.

\section{Methodology}

\subsection{Research Design}

The study was a case study design a brain child of qualitative method. Consistence with Yin (2012), a case study is more suitable when the goal is to provide and answer to "how" and "why" questions which aim to explain a certain phenomenon. The design helped understand how parental support influences career development of youths with intellectual disabilities and whether parents are practitioners.

\subsection{Research Sites}

The study was conducted at Chipembi Farm College, Chisamba in Central Province, Kabwe School for Continuing Education, Kabwe in Central Province and the National Vocational Rehabilitation Centre, Ndola on the Copperbelt Province where youths with intellectual disabilities from across the country are offered skills training.

\subsection{Target Population, Sample Size and Sampling Procedure}

The population consisted of all youths with intellectual disabilities at the named sites, their lecturers and their parents. The target population was 390.The sample comprised sixty (60) respondents; fifteen (15) youths with intellectual disabilities, their parents (30) and their lecturers (15).

\subsection{Research Instruments and Data Collection Procedures}

The study used semi-structured interviews, observations and Focus Group Discussions (FGD) to collect data. These were deemed appropriate because interpretivist researchers favour to interact and to dialogue with the studied participants (Wahyumi, 2012). Semi-structured interviews were administered to all respondents FGD were conducted to youths only. Observation was employed to assess the self-esteem of youths with intellectual disabilities. For triangulation purposes, other sources such as documentary study were consulted.

\subsection{Data Analysis}

Data analysis commenced in the field. The descriptive method was used to analyze it. Data collected, was categorized into emerging themes.

\subsection{Ethical Considerations}

Ethical considerations such as; seeking permission from the university ethical committee, site authorities and respondent issues of confidentiality were taken into account and other basic research conventions. All respondents were given chance to consent their participation in the study and their identity was kept anonymous. For youths with intellectual disabilities, consent was also sought from site authorities.

\subsection{Validity}

As a way to validate contents, the report was peer reviewed.

\section{FINDINGS AND DISCUSSION}

\subsection{Factors that Affect Parental Support}

The study revealed that parental support is affected by income, parenting style, education level or lack of knowledge, parental expectations and the child's disability. As regards income as a factor, one parent said;

Kwena, ukusapota umwanabwino kanopali apakuuma ukuboko. (For one to support a child in whatever way, one should have money or resources).

Such a response shows that parents recognize the need to support their children but are limited by income. This economic vulnerability is an indicator of poverty and deprivation possibly based on low income (Banks, Maître, McCoy and Watson, 2016). This finding mirrors that of Kibera and Kamikoti 
(2007) who found that parents who had high income had the capacity and willingness to support their children's education. When parents are financially stable, they are able to support their children, provide for them or pay their school fees. Similarly, Brofenbrenner's macrosystem encompasses the social economic status which offers the opportunity to spend on an individual or using the family's income to provide for the developing child (Krisnan, 2010). The better the parental economic status, the better the support, the better the development of the child.

Finding indicated that parenting style affected parental support. A prototype response came from a lecturer who said;

Generally, when parents have better income, they support their children.....however not all.... Some parents do not just care about the wellbeing of their children.

This finding mirrors that of Olaosebikan and Olusakin (2014) who found that child rearing practices determine the way parents support their children. Parents who are less responsive may not support their children not because they have no resources but because they might be of neglectful style. Consistent with Armstrong (2014), neglectful parents are characterized by low responsiveness and low demandingness. In addition, they are more passive, of low warmth, rejecting, not attached and give little or no input in many important decisions made by adolescents. Therefore, it is likely that even if some parents in this study had resources, they did not support their children because they were in this category.

The study also revealed that parental support is affected by expectations parents have on the child. One lecturer observed;

What I have noticed is that the nature of disability affects the support that parents give to their children. Children with intellectual disability have for a long time been treated differently as compared to those with other disabilities. Parents normally feel spending money on children with disabilities is like throwing money in a bottomless pit.

Similarly, one parent noted;

Benangu bamayangana pavamene mwana angakwanise kucita bakalibe kumusupota. Bamaika nzelu kulibaja balinanzelu.(Some parents look at potentiality before they support their children at school. they concentrate on those that do fine).

This finding mirrors that of Newman (2009) who found that parents of children with intellectual disabilities have low expectations. Therefore, it would appear that most parents in this study had low expectations which obviously originated from the presence of the disability and consequently affected their support. Brofenbrenners' mesosystem also assumes that beliefs about disability negatively affect parental expectations and how parents relate with the child impacting negatively on career development of an individual. Conversely, Brofenbrenner also assumes that disability can be associated with lower levels of social interactions suggesting a proximal cause of underdevelopment in children (Krishnan, 2010). Equally, parental expectations are likely to depend on the context in which the family finds itself in such as resources or supportive neighbours. The more supportive the neighbours or community are to the family, the better the family will function to the advantage of the developing child.

Study findings also showed that knowledge about the disability affected parental support.

Uyuumwana inenshaishiba bwinobwino ifyakumusenda, nefyo engacita mwandi. Tapaba aba ndondolwelako bwinobwino. (I do not have information about my child's disability and how to help him. No one has ever explained to me nicely).

Banks et al., (2016) observe that at the time of diagnosis of the child's disability parents find their expectations being shuttered. When there is a disability, in spite of the strengths of the child, the disappointed parents develop negative attitudes towards the child (Chandramuki, Indiramaa and Mysore, 2012). The possible explanation for this is that parents are not fully educated on the condition of their child. It is important to note that all parents develop expectations of their children's education based on the information provided by health practitioners, school or media and some parents may hold values that place children with disabilities' role and reflect less emphasis on occupational preparation (Banks et al., 2016). Consistent with Brofenbrenner's exosystem, if parents lack 
knowledge about a disability, it will negatively affect their interaction with the child and career development. Heward (2010) also observes that sometimes parents could have wrong information as regards their children's condition. In this regard, families with limited economic resources tend to direct them first to children without disabilities, giving less hope and encouragement to those with intellectual disabilities. Hence, parents should have a better understanding of their children's abilities. This calls for the need for parents to be provided with information about intellectual disability, career options available and guidance on support to their children to enhance career development.

Findings indicate that parents' view on support on their children was on finances. A lecturer noted;

Some parents fail to avail themselves to their children even if they have no resources. Support does not only mean payment of fees...

It is understandable that parents thought support meant provision of finances, yet support takes different forms such as moral, emotional, social spiritual or physical. Children's career development requires moral, social emotional, spiritual or physical.

\subsection{How Parental Support Influences Career Development of Youths with Intellectual Disabilities}

Findings indicated that parental support influences career development through being motivational and encouraging. Parental support also influences career development through parents showing interest in their children's activities. One female parent with tertiary education and in formal employment said:

When children are supported, they feel loved, confident and morale to try out different activities.

This finding mirrors that of Keller and Whiston (2004) who state that when children are supported, they are motivated to perform better. In addition positive behaviors such as showing support, interest and communicating openly through interactions can enhance career development. On the other hand, negative behaviours such as pushing and controlling done also done through interactions can be detrimental (Kerka, 2000). Brofenbrenner's mesosystem assumes that parents' involvement in the education of their children if mutual will result in microsystems functioning well leading to positive career development for the child.

The study revealed that parental support influences career development of youths with disabilities through giving them morale or motivation. In this study though, 4 youths said their fees were paid by their parents who also provided groceries. In this study, this support was in form of material or verbal encouragement. Such was an indication that parents were happy with what their children were doing. As such, youths were encouraged to go on and try harder. Similarly, Whiston and Keller (2008) notes that when children are fully supported, they are motivated to do better. Whiston and Keller (2004) also found that students who feel supported and loved by their parents have more skill in thinking about careers and the world of work than when they do not feel supported and loved. Consistent with Brofenbrenner's theory, the more encouraging and nurturing these relationships and the places are, the better the child will be able to develop. This support could have originated from the fact that parents loved their children, understood their responsibility of support and had some expectations.

However, most (22) parents in this study were reported not to be involved in the training of their children as they did not; pay for their children, visit their children at school or provide inadequate groceries and of correct standards. Prototype responses from some of the 11 youths were: I am on bursary, the Dominican sister' pay for me or the government pays for me. This finding mirrors that of Maltby (1992) who found that education of children with disabilities was left as the responsibility of churches and well wishers. The possible explanation for this finding could be because these youths were those with intellectual disability who are perceived to be low achievers resulting in low parental expectations. Conversely, Newman (2009) found that parents of children with intellectual disabilities had low expectations. Similarly, Cosgrove et al., (2014) also found that parents were less likely to expect them to go further. On the contrary, Chandramuki et al., (2012) argues that many of the children with disabilities can be high achievers in creative activities but parents fail to recognize and encourage these strengths. This state of affairs can be detrimental to the career development process 
of youths with intellectual disabilities. This act shows that the parents overlooked their vital role of sponsoring their children at the training institutions. This could have reduced the morale for these youths.

Similarly, Bronfenbrenner's Mesosystem assumes that the beliefs about disability affect how parents relate with the child thereby affecting development positively or negatively. In addition, the expectations that parents have based on the disability affects the support they will render and consequently career development. Furthermore, at the mesosystem level, relationships of parents and community members such as church are also a factor. These can be helpful to the family in providing the necessary support a child needs or counseling to the family in times of need thereby influencing the family function and enhancing career development. It should be borne in mind that expectations are subjective predictions about the future and they originate from and affect a person's beliefs, knowledge experience and behavior (Banks et al., 2016).

Based on the findings, it is likely that most youths were from neglectful parents. According to Armstrong (2014), this parenting style is characterized by low demands, low responsiveness and little communication. These parents seem to be detached from their children's life and in extreme cases, may neglect or reject their children. Their children may lack self-control, have lower self-esteem and are less competent than their peers. It is also possible that some of the youths were from highly neglectful environment which did not have clear rules and expectations for high achievement leading to low motivation and poor performance negatively affecting career development. Thus, it is essential that parents are equipped with appropriate knowledge and skills on child rearing so that they can fully support and better guide their children for positive career development.

In this study, it was clear that if there were any authoritative parents, then they were very few. Authoritative style gives emotional security to their children with a sense of calm and autonomy and they assist their children to be successful in school activities (Armstrong, 2014). Secondly, authoritative parents explain the consequences of their children's actions. Explanations give children a sense of knowledge and understanding of their parents' principles, desires, and goals that are associated to school context. These parents involve in reciprocal contact with their children. They support their children, encourage them to do well academically and explain the need for education in order to become a successful adult. Thus, children growing up in the authoritative environment have better overall well-being and higher performance in school related activities (Armstrong, 2014). It can therefore be deduced that the 4 youths who were paid for had authoritative parents. This calls for the need to empower parents with parenting skills that can enhance career development.

\subsection{Parental Support Practices in Career Development of Youths with Intellectual Disabilities}

Findings showed that only 8 parents paid for their children at school. It is no doubt that this support acted as a motivating and encouraging factor in enhancing career development of the paid for youths. The support also showed that the parents loved their children and had interest in what their children were doing. This finding is in concurrence with that of Whiston and Keller (2008) who found that parental support was additionally motivating when parents showed interest, support and involvement in student's vocational activities. When children are loved and supported by their parents, they develop more confidence in their own abilities to find career information. They also become confident to choose a career that would be exciting and interesting to them. Similarly, Hairston (2000) notes that parents were influential because they provided support that eased respondents' apprehensions about vocational preparation. In Brofenbrenner's mesosystem level are relationships between the child's school and parents. If parents are able to conform to the demands of the school, then the relationship influences career development positively.

Another explanation for these results could be the desire for parents to prepare their children for a world that does not expect them to succeed. Therefore the operating message in such parents could be; I want you to show that you are able. Youths in this study internalized the parents'expectations and used them as a motivating factor. Similarly, Brofenbrenner's mesosystem assumes that parental expectations influence the support parents give their children. These expectations arise from the way the community and the neighbours view the disability. In this case, it appears that the driving force for parents to encourage their children was to perform contrary to societal expectations. 
Findings indicate that almost all the youths (14) said that their parents provided them with some groceries of varying types and quantities. One parent said; We provide groceries. Yet, Hairston (2000) argues that parental support and interest acts as a motivating factor in children's' career development. Parental support and encouragement are important factors that have been found to influence career development. With a strong family system, individuals develop a sense of efficacy. Individuals develop confidence in themselves and their ability to learn, persevere and overcome odds. They develop a 'can do' spirit which leads them to use such skills in other areas of their lives. Such persons consider adversity normal and work through their limitations as an opportunity to learn and grow. Consistently, Brofenbrenner's theory, assumes that although the exosystem does not affect the child directly, it impacts on the well being of those who come into contact with the child. Secondly, policies and decisions made at a wider level like at governmental or institutional level indirectly affect the developing child.

In this study, although parents provided groceries to their children, most of them were reported to have been providing very little or of low standardswhile some none at all. A lecturer said;

For those parents that visit, some bring groceries while others do not. Others bring not only more than enough but also assorted while others bring just a few. This brings a lot of frustrations to those who are not visited by their parents. We have had cases wheresome youths simply packed and left saying their parents did not want them.

This probably explains why most of the youths were not excited or eager to explain in detail the support they got from their parents. This is a clear indication that the support was neither motivating nor encouraging. The probable explanation for this lack of support could be that the parents had negative attitudes towards youths with intellectual disabilities. It is also possible that parents had spent a lot after the diagnosis of the children hoping to heal their children to no avail. This failure could be frustrating and demotivating to the parents. Brofenbrenner's mesosystem assumes that beliefs about disability affect how parents relate with the child.

This finding shows that much as the youths said they were given some groceries, parents left out an important role that of paying fees for their children to the Government and NGOs. This in itself could have been a de-motivating factor to the youths which probably affected their career development. This obviously made youths not to see their parents as persons who have the greatest impact on their career development.

In addition, most parents did not conform to the demands of the institutions of visitations. One lecturer lamented;

We have days that parents are supposed to visit their children but very few come. We emphasize on the need for them to visit but there is apathy from most parents.

This finding contradicts that of Kerka (2000) who found that parents took time to attend to school programs such as visitations and meetings. Conversely, the most important parental behavior that influences career development is that basic loving and supportive parent behavior, for example, parents telling a child that they are interested in their opinions, providing for the child or visiting them at school (Whiston \& Keller, 2008). When children feel loved or supported, by their parents, they develop more skills in thinking about careers and the world of work than when they are not loved and supported. A positive environment in the family such as support in career choices and guidance is more linked to more positive outcomes in career development. This entails that parents in this study missed important interactions with the lecturers that would have enhanced their functioning. As such, Kerka (2000) warns that the absence of support and encouragement can lead to flouring, the ability to develop and pursue a specific career focus.

The policy document Educating our Future (1996) has a gap in service provision. It was noted that in all the institutions under study, special education policies only focused on inclusion. Nothing pointed to the role of parental support in career development. Likewise, school policies on special education are within the exosystem of the theory (Krishnan, 2010). Equally, parental workplace schedules can affect processes that occur in the family and consequently affect the development of the child. If parents cannot get time off and attend meetings at the institutions as was the case with some parents in this study, parents will have limited interactions with lecturers thereby influencing youths' career development adversely. 


\section{CONCLUSION}

The study concludes that parental support is affected by income, parenting style, education level, lack of knowledge, parental expectations and the child's disability. Findings indicated that parental support influences career development of youths with intellectual disabilities through being motivational and encouraging to children. It also influences career development of youths with intellectual disabilities through interest shown by parents to children's activities. However, although most parents had knowledge of parental support, most (22) were not practitioners as reflected from the failure to pay their children's fees, pay them visits or involve themselves in children's activities.

Based on these findings the following is recommended;

1. All training institutions should shift from partnering with parents only for cost sharing but also focus on how parents can support their children's career development.

2. The government through Ministry of General Education should form a Network Support System for parents of children with intellectual disabilities. This would help parents develop confidence, self esteem assertiveness which would positively affect parenting styles resulting in attitude change.

\section{REFERENCES}

[1] Armstrong, K. H. (2014) Evidence-Based Interventions for Children with Challenging Behavior, DOI 10.1007/978-1-4614-7807-2_2,

[2] Banks, J., Maître, B., McCoy, S and Watson, D. (2016). Parental Educational Expectations of Children with Disabilities. RESEARCH SERIES

[3] Bronfenbrenner, U. (1999). Ecology of the Family as a Context for Human Development. Research Perspectives. Developmental Psychology, 22, 723-742.

[4] Central Statistics Office (2012). 2010 Census of Population and Housing. National Analytical Report Vol 11. Lusaka: CSO.

[5] Cuiting, L. \& Kerpelman, J. (2007). Parental Influences on Young Women's Certainty about their Career Aspirations. Sex Roles, 56, 105-115. doi: 10.1007/s11199-006-9151-7.

[6] Dietrich, J. \& Salmela-Aro, K. (2013). Parental Involvement and Adolescents' Career Goal Pursuit during the Post school Transition. Journal of Adolescence, 36 (1). ISSN: 0140-1971.

[7] Dube, O. (2011). Research: From Idea to Narrative, incorporating Five Qualitative Enquiry Traditions. Lusaka ZAOU.

[8] Duffy, R. D. \& Dik, B. J. (2009).Beyond the Self- External Influences in the Career Development Process. Career Development Quarterly, 58, 29-43.

[9] Ministry of Education (1996) Educating our Future. Lusaka. Zambia Educational Publishing House.

[10] Ginevra, M. C., Nota, L., \& Ferrari, L. (2011). Parental Support in Adolescents' Career Development: Parents' and Children's Perceptions doi: 10.1111/j.1467-8624.2010.01447.x

[11] Cosgrove, J. C., Mckeown, J. Travels, Z., Lysaght, O., NiBroin and Arder, P., (2014). Educational Experiences and outcomes of Children with Special Education Needs. A Secondary Analysis of Data from Growing Up in Ireland Study. Trim: NCSE.

[12] Hairston, J.E., (2000). How Parents Influence African-American Student's Decision to Prepare for Vocational Teaching Careers. Journal of Career and Technical Education. USA: Digital Library and Archives.

[13] International Labour Organization (2015).///D:/Documents\%20and\%20Settings/Dell/My\%20Documents/ population\%20of\%20MR.htm. Retrieved 20/03/15.

[14] Keller; B. K., Whiston, S. C. (2008).The Role of Parental Influences on Young Adolescents' Career Development.Journal of CareerAssessment, 16, 198-217.

[15] Kerka, S. (2000). Parenting and Career Development. Erick Digest No: 214

[16] Kibera, L.W. \& Kamokoti, A (2007). Fundamentals of Sociology of Education with Reference to Africa. Kenya: University of Nairobi Press.

[17] Krishman, V. (2010). Early Child Development: a Conceptual Model. ECMap. New Zealand.

[18] Maulik, P.K, Harbour, C. K. (2010). Epidemiology of Intellectual Disability. In: JH Stone, M Blouin, editors. International Encyclopedia of Rehabilitation. Available online: http://cirrie.buffalo.edu/encyclo pedia/en/article/144/ 
Parental Support in Career Development of Youths with Intellectual Disabilities in Selected Skills Training Institutions in Zambia: Are Parents Practitioners?

[19] Munyingi, L. (2012). Factors Affecting Career Choices of Female Students in the Kenyan Tertiary Institutions: A Case of US of International University USIU-Africa. Kenya : University of Nairobi.

[20] Newman, L. (2009). The Post High School Outcomes of Youth With Disability Up to 4 Years after $\quad$ High School. A report from the National Longitudinal Transition Study 2 (NLTS 2). National Centre for Special Education Research.

[21] Nord, D. (2012). People with Disabilities in America's Workforce: Time for Fresh Thinking Impact Vol 25,1

[22] Olaosebikan, O I. \& Olusakin A, (2014). Effect of Parental Influence on Adolesents' Career Choice in Baldagry Local Government Area of Lagos State, Nigeria. Journal of Research and Methods in Education. Vol 4, 44-57.

[23] Rodrigues, S., Jindal-Snape, D., \& Snape, J.B. (2011). Factors that Influence Student Pursuit of Science Careers; The Role of Gender, Ethnicity, Family and Friends. Science Education International, 22(4), 266273.

[24] Schultheiss, D. E. P., Kress, H. M., Manzi, A. J., \& Glasscock, M. J. (2001). Relational Special Topic Report of Findings from the National Longitudinal Transition Study-2 (NLTS2).SRI International.

[25] Turner, S. L., Alliman-Brissett, A., Lapan, R. T., Udipi, S. \& Ergun, D. (2003).The Career- Related Parent Support Scale.Measurement and Evaluation in Counselling and Development, 32 (2) 83-94.

[26] Wahyuni, D., (2012). The Research Design Maze: Understanding Paradigms, Cases, Methods and Methodologies, Journal of Applied Management Accounting Research, Vol. 10, 1. 69-80.

[27] Way, W. L., and Rossmann, M. M. (1996). Lessons from Life's First Teacher: The Role of the Family in Adolescent and Adult Readiness for School-to-Work Transition. Berkeley, CA: National Center for Research in Vocational Education, (ED 396 113)

[28] Whitson, S.C., \& Keller, B.K. (2004). The Influence of the Family of Origin on Career Development: A Review and Analysis. Counseling Psychologist, 32 (4) (Jul 2004): 493- 568. College Park, MD: Sage Publications, Inc. ISSN: 00110000. URL: http://search.proquest.com/docview/203274703?accountid= 12598. doi10.1177/0011000004266009.

[29] World Health Organization and World Bank (2015) ///D:/Documents\%20and\%20Settings/Dell/My\% 0 Documents/population\%20of \%20.htm. Retrieved 20/05/15.

[30] Yin, R. K. (2012). Application of Case Study Anthology. Sage: Thousand Oaks, C.A.

\section{AUTHORS' BIOGRAPHY}

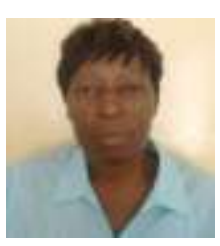

Viola Mathatha, has 23 years of teaching experience. She taught at a secondary school for 20 years before moving to Kwame Nkrumah University where she is currently lecturing in the School of Education, Department of Special Education.

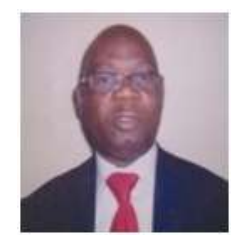

Dr. Daniel Ndhlovu, holds a PhD (Special Education), has 32 years teaching experience and is formerly Assistant Dean, Post Graduate, School of Education, University of Zambia. He is currently Director, Institute of Distance Education, University of Zambia and lecturer in the School of Education, Department of Educational Psychology, Sociology and Special Education.

Citation: Mathatha, Viola, and Ndhlovu Daniel. "Parental Support in Career Development of Youths with Intellectual Disabilities in Selected Skills Training Institutions in Zambia: are Parents Practitioners?." International Journal of Humanities Social Sciences and Education (IJHSSE), vol 4, no. 11, 2017, pp. 15-25. doi:http://dx.doi.org/10.20431/2349-0381.0411003.

Copyright: () 2017 Authors. This is an open-access article distributed under the terms of the Creative Commons Attribution License, which permits unrestricted use, distribution, and reproduction in any medium, provided the original author and source are credited. 